\title{
Translation Constraints and Procedures to Overcome them in Rendering Journalistic Texts
}

Sabir Hasan Rasul, PhD in Translation Studies, University of Human Development

\begin{abstract}
Even the simplest, most basic requirement we make of translation cannot be met without difficulty: one cannot always match the content of a message in language A by an expression with exactly the same content in language B, because what can be expressed and what must be expressed is a property of a specific language in much the same way as how it can be expressed.
\end{abstract}

(Winter 1961: 98, quoted in Baker 2011: 92)

Translation cannot be done without difficulties and constraints, no matter what languages are involved. It is more so in translating between English and Kurdish, which are marked by different linguistic systems and socio-cultural incongruities. When encountered with translation constraints, translators usually resort to employing translation procedures in a bid to eliminate such difficulties and ultimately achieve translation adequacy. This study aims to identify the patterns of translation constraints encountered when translating journalistic texts from English into Kurdish, as well as identify the patterns of translation procedures employed to overcome such constraints. The aim behind this endeavour is to first better understand the working process of professional or semiprofessional journalist-translators working into Kurdish, and secondly, to heighten trainee translators' awareness and introduce them to the nature and patterns of translation difficulties and the translation procedures undertaken to overcome such difficulties.

\section{Introduction}

Taking a qualitative approach, this study surveys the translation of 45 English journalistic texts along with their Kurdish translations. The data was originally collected for the purpose of my $\mathrm{PhD}$ thesis to identify the patterns of translation procedures and strategies employed in translating journalistic texts in the Kurdish media (for more details of the data, see Rasul 2015: 78). 
It is important to highlight at the outset that it is generally hard to identify what counts as a translation constraint, since translation constraints are bound to various factors such as the purpose of the translation, the nature of the target readership, the translator's level of experience, etc. What is considered a translation difficulty for an individual translator may not be problematic for another, depending on the level of competence, the translation resources available, etc. However, as a result of the analysis of the collected data, we can identify some general trends and phenomena that seem to have posed translation difficulties and constraints, and have required the translators to resort to various translation procedures.

\section{Translation constraints at linguistic level}

Different languages have different linguistic systems. This leads to translation difficulties between almost all languages. The most remarkable constraints encountered at linguistic level can be categorized into lexical, semantic and syntactic levels.

\subsection{Lexical level}

As far as the data is concerned, the patterns of difficulties encountered at the lexical level can be put into three categories: (1) lacunae in lexicon; (2) collocational constraints; and (3) limited range of word class of some TL equivalents.

\subsubsection{Lacunae in lexicon}

Vinay and Darbelnet (1995: 32) use the term 'lacunae' to refer to "gaps [...] in the target language (TL) which must be filled by corresponding elements, so that the overall impression is the same for the two messages". The lacunae are "often associated with the problem of translation difficulties" (Anokhina 2013: 172). Although lacunae in the lexicon can belong to any type of lexical terms, in the case of translating journalistic texts from English into Kurdish, abstract and conceptual terms constitute the most common type. In the data, various translation procedures are employed to tackle the issue of lacunae in lexicon, as follows:

a. Borrowing: this involves the use of foreign words in the target text (TT). In translations between English and Kurdish, lexical gaps constitute a major factor in implementing the borrowing translation procedure. For instance, having no Kurdish equivalent for the word conference, its English borrowing كوّنفرانس is used in translation into Kurdish. Likewise, since Kurdish does not have a ready equivalent for the term curriculum, its Arabic borrowing مدنه is used in the Kurdish translation. 
b. Generalization: this involves the replacement of a source language (SL) word by a more general word in the target language (TL). Generalization is a handy procedure when translators face a lexical gap. However, in translating by generalization translators may run the risk of meaning loss, since in generalization a piece of information or an aspect of meaning is always lost. Consider the translation of the word professor by generalisation as ['teacher'], where the TL word does not indicate 'a teacher at the university level', unless the context suggests that.

c. Particularization: it is the opposite of generalization; it involves the replacement of a source language word by a more specific word in the target language. The procedure can sometimes be used to overcome the problem of lexical lacunae, such as translating the term theocracy by particularization as و لَاتنّكى ئيسلامى ['an Islamic country'].

d. Near-synonymy: it is defined as "a near TL equivalent to an SL word in a context, where a precise equivalent may or may not exist" (Newmark 1988: 84). Translating by nearsynonyms seems to be one of the most practical and appropriate procedures to deal with the issue of lexical lacunae. Dictionaries and thesauruses, in general, can be particularly useful in this regard. For instance, translating abuse into its near-synonym توندونيزى ['violence'] and rendering dysfunctional economy as ئابورى شكستخواردوو ['failed economy'].

e. Paraphrase: this is sometimes considered an ideal procedure in translating concepts expressed by the source items that are not lexicalized in the TL (Baker 2011: 38). Consider below the translation of the concept potential by paraphrase as [ئكَرى سهركهوتن ['possibility of success']. (For ease of understanding, the English ST extract is followed by its Kurdish translation, which is followed by its back-translation in square brackets).

\section{Example 1:}

Iraq has a great deal of promise, a great deal of potential...

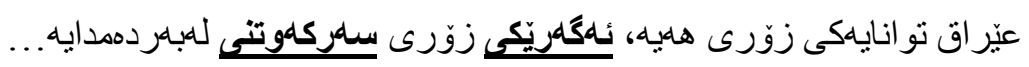

['Iraq has a great deal of capacity, it has a great deal of possibility of success...']

f. Omission: this occurs when an SL element (a word, a phrase, an utterance, etc.) is simply missed out in the translation. Rasul (2015: 210) claims that "omission seems to be a common characteristic of journalistic translation, especially when translators work under constraints of time and space". As a dispreferred procedure, more than often not, translators omit a term or concept that lacks a one-to-one Kurdish counterpart, such as the omission of 
the term would-be in the following example, which does not have a ready equivalent in Kurdish:

\section{Example 2:}

"Help from America can be misunderstood," one would-be Egyptian politician delicately explained to The Post a few days ago.

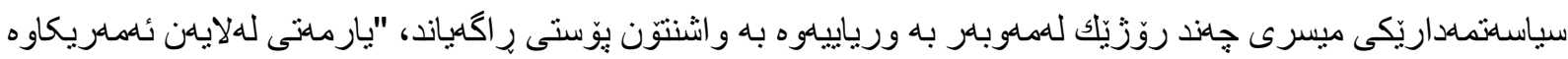

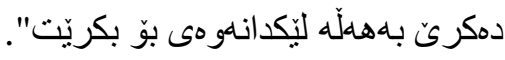

['An Egyptian politician carefully told The Washington Post a few days ago: "Help from America can be misinterpreted".']

\subsubsection{Collocational constraints}

Collocation is defined as "the occurrence of two or more words within a short space of each other in a text" (Sinclair 1991: 71). Different languages have different collocation systems. This difference can sometimes result in odd collocations which, if not eliminated in the proofreading process, will sound unnatural in the TT. For instance, Kurdish has direct equivalents for low (نزم) and chance (دمرفهن). However, while low and chance collocate normally, their Kurdish equivalents do not collocate at all. Similarly, while create and job make a good collocation, their Kurdish equivalents دروستكردن and do not come together naturally. As a handy procedure, translation by near-synonymy can be particularly useful to eliminate collocational discrepancies. Thus, one may

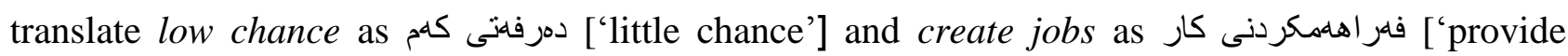
jobs'].

\subsubsection{Limited range of word class}

The limited range of word class or word form is one of the immediate difficulties in translating from English into Kurdish, which makes direct translation impossible. The the analysis of the data suggests that Kurdish seems to be less flexible than English in the range of possible words that can be derived from a root word, or rather, English is perhaps more flexible than many other languages in this respect. For example, Kurdish has two equivalents for equipment ( كهر مسته/ (ئاميّر but not for equipped .Likewise, Kurdish has two counterparts for rank as a noun (يله/ نمره) but it does not have a related verb form. In the data, various translation procedures have been adopted to overcome the issue of limited range of word class, such as:

a. Transposition: Transposition at the lexical level is mainly concerned with a shift in the word class. When the TL does not have a corresponding word class for a given SL word, the shift is obligatory. 
For instance, Kurdish has an equivalent for the verb visit, but it does not have an equivalent for the agent noun form (visitor). Thus, as a possible translation procedure, the word can be rendered by transposition as in the phrase any visitor to the Kurdish region > ريّى كوردستان ردانى هلمسيّك سيفر كههد [كات ['anyone who visits the Kurdistan region'].

b. Paraphrase: Paraphrase is often a practical, but not always a preferable, option to translate many words and terms that resist direct translation. Paraphrasing SL words with limited word class in the TL is not an exception. Consider the following extract, where the word visitor is paraphrased.

\section{Example 3:}

A visitor to Erbil, particularly, would be struck by the current consumer and construction boom.

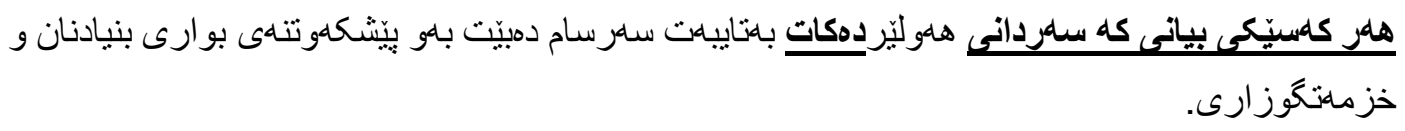

['Any foreign person who visits Erbil would be particularly surprised by the development in the field of construction and services.']

c. Near-synonymy: Occasionally, translation difficulties encountered due to limited range of word class can be eliminated by using a near-synonym, i.e. using a formally different but semantically related word. For instance, in the following extract, the translator chose to render visitor by its nearsynonym ميوان ['guest'], which is at the same time a more expressive term, since it has a warm connotation.

\section{Example 4:}

It is one of the few places in Turkey where neither blasting pop music nor flatscreen televisions entertain visitors...

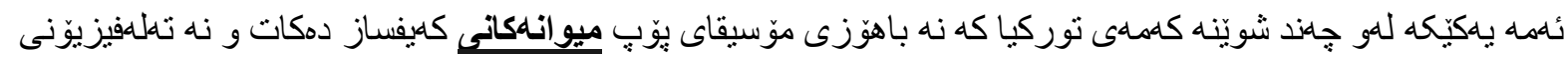

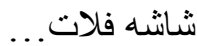

['It is one of the few places in Turkey where neither blasting pop music nor flatscreen television entertains the guests...']

d. Omission: It is practically possible to omit any bit of language in translation, although this always leads to meaning loss. In the data, more than often not, words marked by limited range of word class زياد ده (jore simply dropped in the translation. For instance, Kurdish has an equivalent for increasing كات (ك), but not for its adverb form increasingly. Consequently, the word increasingly is simply dropped in the translation of the following extract:

\section{Example 5:}


Turkey has been playing an increasingly influential role in Iraqi politics...

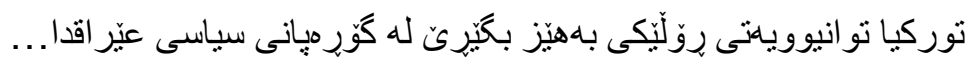

\section{['Turkey has been able to play a strong role in Iraqi political arena... ']}

e. Translation couplets: other cases of limited range of word class are more sophisticated, and can be eliminated only by utilising two translation procedures or 'couplets', to use Newmark's term (1988: 91). For example, Kurdish has no equivalent for the verb reported or its noun form report, but the latter is used in Kurdish as a borrowing. So, the phrase the Financial Times reported is translated as

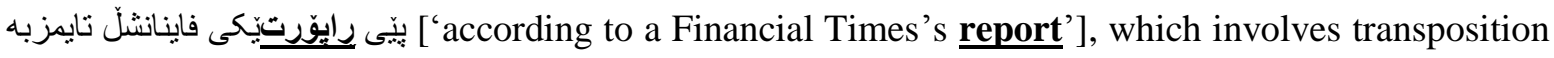
(a shift from verb to noun) as well as borrowing. Similarly, the term genocidal in the phrase $a$ دكتاتوريّكى تاوانبار به جينّوسايد ['a dictator accused of genocide'].

As a final remark, the examples display a lack of consistency in the procedures used by different translators to deal with the same translation difficulty. The translations of the term visitor, discussed above, are clearly indicative of such inconsistency across the data, where different procedures (transposition, paraphrase and near-synonymy) are adopted by different translators to overcome the same translation constraint.

\subsection{Semantic level}

Since meaning and equivalence of meaning are at the core of translation, the semantic aspect of translation is in principal non-negotiable, however much actual translation may suggest otherwise. With regard to the data, the patterns of difficulties encountered at this level can be put into three categories: (1) limited range of meaning of some TL equivalents; (2) idioms; and (3) metaphors.

\subsubsection{Limited range of meaning}

The limited range of meaning of some Kurdish equivalents causes a real translation impediment. More than often not, English words and terms have to be translated into Kurdish nearsynonyms because of the limited semantic range of their supposed TL equivalents. For example, the semantic range of Kurdish equivalents for English words such as key ${ }^{l}$, room and poor are mostly

\footnotetext{
${ }^{1}$ It is worth noting that, as a new trend, the Kurdish word for key (كليل) is nowadays also used in its nonpropositional sense, but its usage is limited to expressions such as كليلى سلركون ['the key of success'] and كليلى بهختهوهرى ['the key of happiness'], possibly influenced by English.
} 
limited to their propositional meanings, while these words have a wider range of meanings in English. In the data, these words are effectively translated by near-synonymy, as follows:

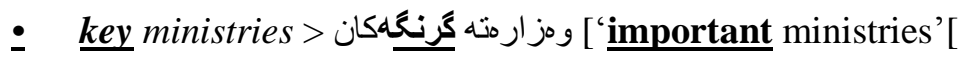

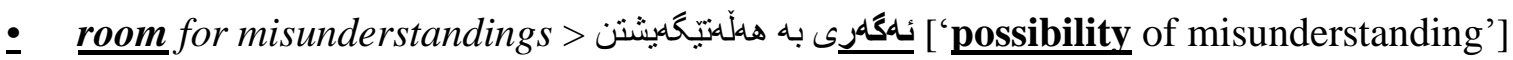

- $\quad$ poor service > ['lack of service']

\subsubsection{Polysemy}

Polysemy is defined as "a situation in which a lexical item has a range of different and distinct meanings or senses" (Dickins, Hervey and Higgins 2002: 239). Since sufficient knowledge of both the SL and TL is a prerequisite for anyone considering a translation career, translators are supposed to be familiar with the various standard meanings a lexical item has. Hence, in principle polysemy should not be a problem for competent and professional translators. The data, however, suggests that even translations produced by professional or semi-professional translators are not free from errors due to the issue of polysemy. For example, the term national has two major senses, as outlined in Collins English Dictionary (2006): (1) 'of, involving, or relating to a nation as a whole', and (2) 'of, relating to, or characteristic of a particular nation'. In Kurdish, the first sense is translated as نيشتيمانيى and the second sense as in rendering the phrases national reconciliation and Iraqi national feeling the translators opted for the first sense as ئشتهو ايیى نهتاهو ميىى and هلمستى نهنتوهيى عبّر اقى , respectively. Given both terms are references to the Iraqi people as a ئاشتاعو ايى ashole, the second sense is the correct one and the phrases should have been translated as , هامستى نيشتيمانى عبّر اقى and نيشتنيمانيى , respectively.

\subsubsection{Idioms}

Idioms are defined as "frozen patterns of language which allow little or no variation in form and [...] often carry meanings which cannot be deduced from their individual components" (Baker 2011: 67). Since idioms are language specific, and some of them are even culture-specific, they are bound to create difficulties in translations between all languages. Baker (ibid: 68) points out two main areas of difficulties in the translation of idioms: (1) "the ability to recognize and interpret an idiom correctly" and; (2) "the difficulties involved in rendering the various aspects of meaning that an idiom or a fixed expression conveys into the target language". Failure to overcome one or both of the difficulties will result in nonsense or mistranslation. 
However, having recognised and interpreted an idiom correctly, translators can make use of various translation procedures to effectively handle idioms in translation, as follows:

a. Calque: Vinay and Darbelnet (1995: 32) define 'calque' as "a special kind of borrowing whereby a language borrows an expression form of another, but then translates literally each of its elements". Translating idioms by calque involves replacing an SL idiom by a TL idiom that has similar meaning and form (Baker 2011: 76). According to Baker (ibid.), it is only occasionally possible to achieve this kind of match. When translating an idiom by a calque, both semantic and formal features of the idiom will be preserved, and at the same time accuracy will be achieved. Consider the extract below, where the idiom come to fruition is effectively translated into its Kurdish idiomatic counterpart:

\section{Example 6:}

Yet, that agreement never came to fruition; Allawi and Maliki failed to come to agreement over the distribution of power.

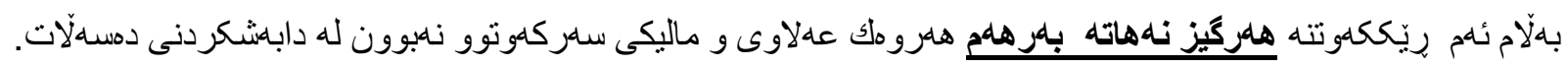

['But that agreement never came to fruition, since Allawi and Maliki failed to come to agreement over the distribution of power.']

b. Communicative translation: if it is impossible to find a TL idiom with similar meaning and form, idioms ought to be translated by equivalence or communicative translation, i.e. replacing an SL idiom by a TL idiom that has the same meaning but a different form. For instance, the English idiom

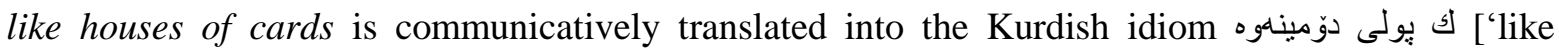
domino blocks'[, which has similar meaning but a different form in the context of the following extract:

\section{Example 7:}

Poor construction still seems to be our weakness. Buildings collapsed like houses of cards...

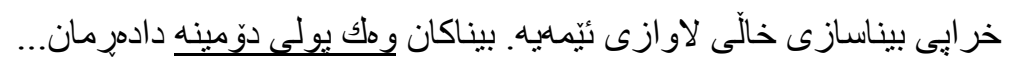

\section{['Poor construction is our weakness. The buildings collapsed like domino}

\section{blocks...']}

c. Paraphrase: If communicative translation is not possible either, translators can always use paraphrase as a possible alternative. Chesterman (1997: 104) considers paraphrase a typical translation procedure for rendering idioms that do not have idiomatic counterparts in the target language. For example, since Kurdish has no idiomatic counterpart for the legal idiom due process - 
short form for due process of law - this is effectively translated by paraphrase as كانيان يبيى ياسا مافهبه ['their rights are to be protected according to law'].

d. Omission: Apart from the translation procedures mentioned above, sometimes translators also omit idioms simply because they do not have counterparts in the TL or it is difficult to work out their meanings. This can be rightly criticised, because by omitting an idiom, although translators can avoid producing a nonsensical translation, the meaning of the message may be compromised. Moreover, the expressivity of the text also will be reduced, since idioms are considered expressive aspects of a language. The following extract is an example in which the idiom back-of-the-envelope is simply omitted in the translation:

\section{Example 8:}

But since being in Egypt, I've been putting together my own back-of-the-envelope guess list of what I'd call the "not-so-obvious forces" that fed this mass revolt.

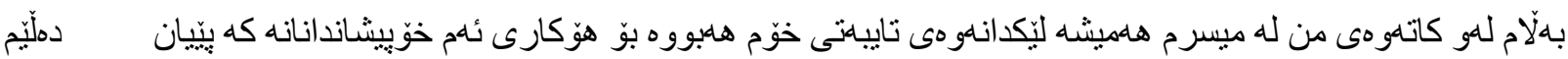
"هيّزى نارِوَشن".

['But since being in Egypt, I've had my own personal interpretation for the reasons of the protests that I'd call the "non-obvious forces".']

\subsubsection{Metaphors}

Metaphors are considered expressive features of a language as they are "a device of the poetic imagination and the rhetorical flourish - a matter of extraordinary rather than ordinary language" (Lakoff and Johnson 2003: 3). Dickins et al. (2002: 147) define metaphor as "a figure of speech in which a word or phrase is used in a non-basic sense, this non-basic sense suggesting a likeness or analogy with another more basic sense of the same word or phrase". Metaphor is seen as the most important of all what are conventionally known as figures of speech, not only because it is the most widespread but also because it presents the most challenging translation difficulties (ibid: 146). Likewise, Newmark (1988: 104) claims that "[w]hilst the central problem of translation is the overall choice of a translation method for a text, the most important particular problem is the translation of metaphor". Metaphor is said to "give rise to difficulties in translation between any two languages, but where the languages concerned are as relatively different culturally and linguistically as English and Arabic, the difficulties are sometimes quite pronounced" (Dickins et al. 2002: 146).

To overcome problems in metaphor translation, various translation procedures can be effectively employed, depending on the nature of the metaphor and the possible equivalents 
available in the TL. This underlines the significance of the translators' knowledge of metaphors not only in the ST but also in the TL (which is usually the translator's mother tongue). The following translation procedures can be particularly useful in handling translation difficulties posed by metaphors:

a. Communicative translation: This involves the replacement of a SL metaphor by a TL metaphor which uses a different image to express the same sense. For example, the metaphor stalemate in the phrase political stalemate is translated communicatively as with similar meaning but different form.

b. Paraphrase: paraphrase is a practical procedure for translating metaphors, although it tends to reduce the expressiveness and vividness of the metaphor. In other words, paraphrasing metaphors involves the transference of sense at the expense of the metaphorical image. Consider the metaphor grassroots, in the following example, which is translated by paraphrase as ['lower levels of people'].

\section{Example 9:}

I think the more we have a democracy from the grassroots, the less likely there going to have kind of the sectarian divisions....

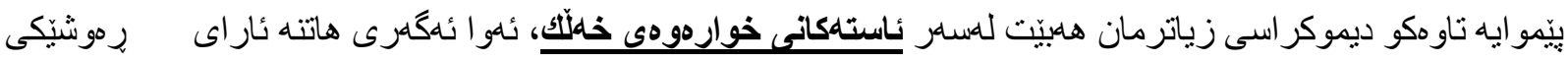

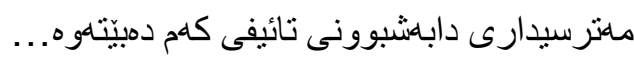

['I think the more democracy we have at the lower levels of people, the less likely

there would be a dangerous situation of sectarian division...']

d. Synonymy: This is particularly useful in the translation of dead metaphors, i.e. the type of metaphor which "one does not normally even realize is a metaphor as in a 'talented' man or the 'arm' of a chair" (Dickins et al. 2002: 149). Examples of metaphors translated by synonymy are: $\underline{\text { bottomless }}$

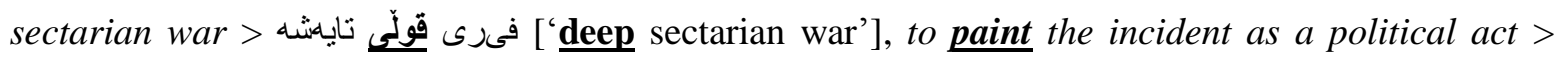
['to interpret the incident as a political act'] and to boost

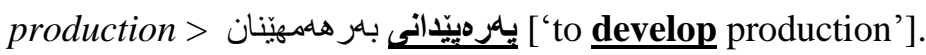

e. Literal translation: this can be sometimes acceptable, again in rendering dead metaphors, especially when the meaning of the metaphor is transparent. For instance, in the sentence Taiwan also edged away from the brink of national suicide, the metaphor suicide is effectively rendered by literal translation as خوّكوزي نيشتنمانى.

f. Omission: although omission is generally not preferred as a translation procedure, the data is not free of the wholesale omission of significant metaphors. Consider the omission of the metaphor booming in the sentence Protests, after all, are bad for business, and business is booming in Kurdistan. The term booming is a common dead metaphor in English business and economics 
reports, which can be translated by sense, i.e. preserving the meaning but eliminating the image conjured up by the metaphor. Thus, the most appropriate translation procedure to translate booming might be generalization, rendering it as له كُششدايه ['developing'].

\subsection{Syntactic level}

Despite being more flexible than other textual levels, translators come across various difficulties at the syntactic level in translations between English and Kurdish. The three most significant translation difficulties encountered at the syntactic level in the data are: (1) lacunae in structure, (2) limited range of possible structures, and (3) voice (active $<>$ passive).

\subsubsection{Lacunae in structure}

Some English grammatical structures do not have equivalent constructions in Kurdish, such as, pre-modifying grammatical structures in English, which are marked by their concision. The phrase gender-based violence is an example of this, as a structure which can be translated by expansion (i.e. the use of more words in the TL) as توندوتيزى لكسامر بنماى جيندمرى [violence on the basis of gender']. Alternatively, the phrase can be translated by reduction (i.e. the use of fewer words in the TL) as توندونيزى جيّندريى ['gender violence']. Another example is the phrase new-found status, which best translated by reduction as يُّكَى نوى ['new status'].

\subsubsection{Limited range of possible structures}

In the construction of some grammatical structures, English seems to be more flexible than Kurdish. For instance, English conditional subordinate clauses can be standardly constructed using if clauses, modal verbs and past participles, whereas Kurdish has only the if clause (ئهكَر) to construct conditional structures. Therefore, English conditional clauses based on modal verbs or past participles have to be transposed into the Kurdish if clause (ئهكار). In that case the transposition involves a shift in the grammatical structure, as demonstrated in the example below:

\section{Example 10:}

Should Iraq be dismembered, I can say that it won't be the Kurds who will be the agents of division.

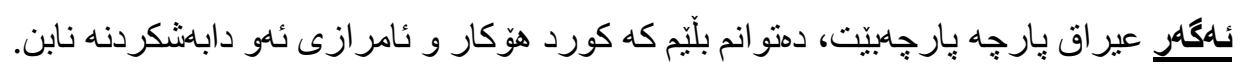

[ 'If Iraq is dismembered, I can say that the Kurds won't be the cause and the means of this division.'] 
Likewise, English is very flexible in the construction of direct reported speech; the speaker can be mentioned at the beginning, in the middle or at the end of the speech. Kurdish, however, has only one possible structure in which the speaker precedes the speech. Hence, when translating English direct speeches where the speaker occurs in the middle or at the end of the speech, the syntactic structure of the ST extract should be transposed to the speaker-initial position structure, as shown in the example below. Otherwise, the translation will violate the conventions of the syntactic structure of Kurdish direct reported speeches.

\section{Example 11:}

"Generally the response to such acts is one of horror but it is an act that also elicits sympathy", says Dr Biggs.

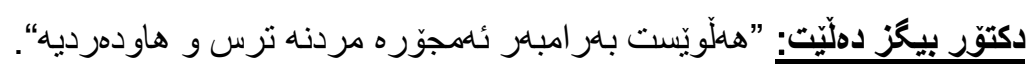

[ $\underline{\text { Dr Biggs says, }}$ "responses towards such a form of death are one of horror and sympathy"'].

Since direct reported speech is very common in journalistic texts, especially news reports, translators have to be very cautious and confine themselves to the conventions of the TL structure. In recent years, some Kurdish media occasionally use unconventional constructions where the speaker occurs at the end of the speech. These instances are most likely produced by inexperienced translators and influenced by English syntactic conventions.

\subsubsection{Voice: Active $<>$ passive}

Another aspect of syntactic level that is likely to cause translation difficulty is that of voice. The voice that works in the SL may not work in the TL. For a translation product to be naturalsounding, translators have to adhere to TL syntactic norms. This may require a structural modulation $^{1}$ from active voice to passive voice or vice versa. Consider the following example, in which the English passive voice has to be translated into active voice in Kurdish, which would otherwise sound extremely odd:

\section{Example 12:}

Scientists discuss the earthquake in Van, but they do not discuss the certainty that Istanbul will be hit by an earthquake.

\footnotetext{
${ }^{1}$ Modulation is defined as "a variation of the form of the message, obtained by a change in the point of view" (Vinay and Darbelnet 1995: 36). A change between active voice and passive is only one type of modulation.
} 
دلّنياييهوه زهمين للمززه ئمستهمبوليش زهمين للهزه دهكمن له شارى وان، بهلام باس لهوه ناكهن كه به زاناكان مناقهشهى ده هلنَّينتيث.

['Scientists discuss the earthquake in Van, but they do not discuss the certainty that earthquake will also shake Istanbul. ']

Although active voice is considered the basic structure that is available in almost all languages, occasionally English active voice structures have to be translated into passive voice in Kurdish, as in the following extract:

\section{Example 13:}

Since Napoleon's invasion of Egypt in 1798, Egyptians have wanted to catch up with the West.

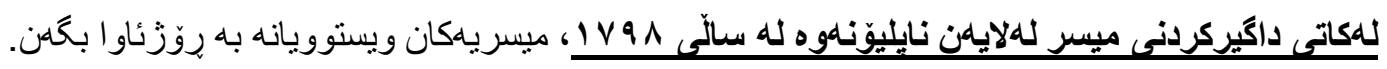

[ 'Since Egypt's invasion by Napolean in 1798, Egyptians have wanted to catch up with the West.']

\section{Translation constraints at cultural level}

It is wise to begin with Nida's (1964: 161) assertion that "differences between cultures cause many more severe complications for the translator than do differences in language structure". When confronted with culture-specific terms, translators need to go beyond the boundary of language and operate in a wider area where language and culture are combined. As far as the data is concerned, the difficulties encountered at the cultural level are of four types: (1) cultural lacunae, (2) proper names, (3) appellative( addressing people's names), and (4) new institutional terms.

\subsection{Cultural lacunae}

This can be either a lexical gap, where a cultural term does not have an equivalent lexical item in the TL, or a semantic gap where an idea expressed in the SL culture does not have a corresponding expression in the TL culture. Consider in the following the two culture-specific terms hawks and doves:

\section{Example 14:}

The surge in Afghanistan barely appeased hawks, while his rhetoric about withdrawal barely pleased doves.

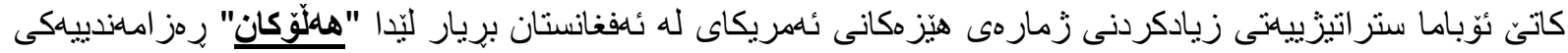

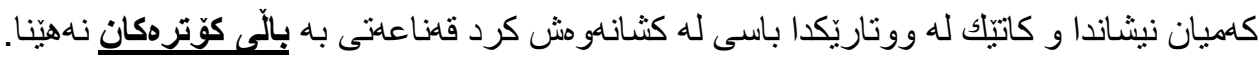


['When Obama decided on the strategy of increasing the American forces in

Afghanistan the hawks showed little approval, and when in a statement he talked

about withdrawal, he could not please the doves' wing. ']

In US political culture, the term hawks refers to the party that favours war and the term doves refers to the party that favours peace. Since the two terms do not have a place in Kurdish culture, they pose a challenging translation difficulty. The terms cannot be directly transferred as they would be incomprehensible to the target readers. On the other hand, it is not the translator's duty to introduce readers to the concepts, which would require a lengthy paraphrase. The translator rendered the terms literally hoping that readers may understand the connotative meanings of the concepts, based on their knowledge of the world and/or perhaps their previous readings where they may have come across the concept. It is worth mentioning that the literal translation of the second term also involves explicitation', translating doves as بالّى كوّترهكان ['the doves' wing'], which indicates that it is a reference to a political orientation.

Regarding semantic gaps as a cultural difficulty, consider the English cultural expression litter louts. Such a cultural expression is meaningful only in the context of the original culture. When translating it into Kurdish, for example, one wonders which translation procedure would sound the most appropriate. In fact, each possible procedure has its disadvantage one way or another. First of all, paraphrase is not a preferred procedure in journalism translation, where brevity is important for time and space reasons. Transference is also ruled out when dealing with expressions rather than individual lexical items, especially since English and Kurdish use different alphabets. Literal translation can be considered a possible procedure, but again it has its disadvantages. In the data, the expression is literally translated as بئز اوهكيّر انى يُشماوه, which sounds unfamiliar to the target readership. Thanks to the context, however, the readers can still perceive it is as an expression originating from British society:

The questions 'litter louts' as we call them in the UK, should ask themselves are: who do I want to pick up after me and how much would I want to pay them to do it?

\subsection{Proper names}

Decades ago, proper names were considered untranslatable. One of the early considerations of the issue of proper names in translation refers back to Zabeeh (1968: 69), who views proper

${ }^{1}$ Explicitation is a translation procedure which is defined as "the technique of making explicit in the target text information what is implicit in the source text" (Klaudy 2009: 104). 
names as "international items which belong to no specific language", believing they cannot and should not be translated. In line with Zabeeh, more than a decade later Newmark believes (1981: 70) that proper nouns locate outside language belonging to the encyclopaedia rather than dictionary, and since they have no meaning or connotations, proper names are "both untranslatable and not to be translated". More recently, Christina Nord (2003: 182) suggests that it is rather a perception to consider proper names untranslatable, because "looking at translated texts we find that translators do all sorts of things with proper names".

The most appropriate procedure for translating proper names is borrowing or transference, which simply involves the conversion of alphabets from the SL into the TL. But translators also need to bear in mind that transferring proper names is not always a smooth and straightforward process, especially between languages using different alphabets such as English and Kurdish, where the transference will inevitably involve transliteration, i.e. adapting to the TL alphabet. As far as English and Kurdish are concerned, discrepancies in the sounds available in the two languages are a source of difficulty in the process of transferring English proper names into Kurdish. Kurdish lacks five sounds that exist in English, namely: $/ \theta /, / \partial /, / \mathrm{y} /, / \Lambda /$ and $/ \curvearrowright: /$ In the absence of an academy or other body to attempt to decide what is appropriate for Kurdish, this discrepancy has caused inconsistency or even inappropriate transliterations of some proper names.

In the data, for instance, the proper name The Times is transliterated as زى نايمز ['Ze Times'], i.e. replacing /ð/ by /z/ as the closest possible sound, which does not seem to be an adequate transliteration. The sound issue could be effectively eliminated by dropping The and transliterating the proper noun as [يموزَنامهى تايمز]['Times Newspaper'].

More importantly, in the case of English and Kurdish translation, cities with two names can be particularly problematic. For example, the cities Tripoli and Heliopolis have different names in Arabic (عرابلس شمس and عر ابلس, respectively). Although the Arabic names are normally used in

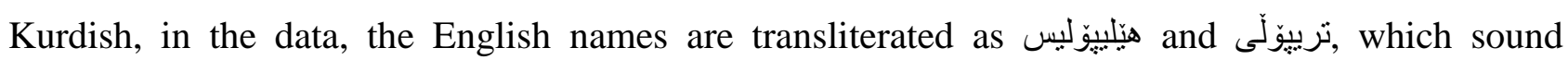
unfamiliar to the target audience.

\subsection{Appellative: addressing people's names}


Obviously, titles such as Mr, Ms, Mrs and Miss are English culture-specific terms, and should be translated by cultural adaptation ${ }^{1}$, i.e. their cultural counterparts in the TL. Thus, Mr. > (transliterated as: Kak) or بهريّ ['respected'], Ms, Mrs and Miss > خاك (transliterated as: Xatw). The real translation issue occurs in the way these titles are used. For example, the form of address in which the title is followed by family name does not work in Kurdish. It has to be adapted into a form that is conventional in Kurdish (e.g. first name + family name), thus Mr. Hashimi >نارق هاثشى ['Tariq Hashimi']. Alternatively, the title can be simply omitted as a way of eliminating the translation constraint, e.g. Mr Obama > ئّباما ['Obama']. It is important to point out that Kurdish does not make use of family name alone, unless it refers to a familiar, prominent figure.

\subsection{New institutional terms}

Established institutional terms generally do not pose translation difficulties. For instance, established institutional terms such as United Nations and European Union have standard

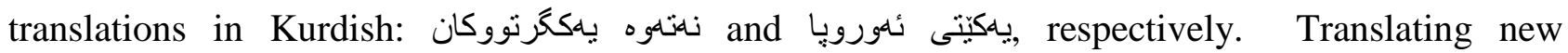
institutional terms, however, seems to be problematic. Institutional terms, especially international ones, usually enter a language through translators. So when translators encounter a new institutional term that has never been translated into their language before, they find it challenging to translate it in a way that is appropriate and comprehensible to target readers. The new institutional term AllParty Parliamentary Group on Kurdistan is an example of such a challenge. The problem with this term is that it has various forms in the SL, such as: APPG, All-Party Group for Kurdistan and AllParty Parliamentary Group (APPG) on the Kurdistan Region in Iraq. So the term does not have an established form in the SL, let alone an established translation in the TL. As a result, the term is translated in three different ways, as follows:

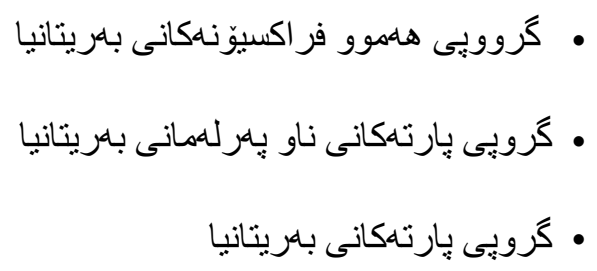

The inconsistency, or rather confusion, in translating the term is a result of the difficulty posed by the new institutional term.

${ }^{1}$ Cultural adaptation is a translation procedure in which "an SL culture-specific term will be replaced by a cultural term that occupies the same cultural situation in the TL and conforms to the TL cultural norms" (Rasul 2015: 78). 
When confronting new institutional terms, Newmark suggests 'translation label' as an appropriate procedure, which involves the literal translation of a term that is put in inverted commas as a transitional rendering (1988: 90). It is noteworthy that transparent new institutional terms are less likely to pose translation difficulties, e.g. Bahrain Center for Human Rights > سانتشرى مافهكانى ['Human Rights Centre in Bahrain'].

\section{Conclusion}

Translation is conditioned by linguistic and cultural factors, and each factor is bound to pose translation difficulties. The linguistic aspect of translation is of a multi-layered nature, consisting of lexical, semantic and syntactic levels. Translators are likely to encounter different translation difficulties at each level. In the data concerned, the difficulties that arise at various linguistic levels have obliged the translators to resort to a wide range of translation procedures, some of them employed effectively, while others can be improved on or even criticised.

At the lexical level, lacunae are an immediate translation constraint, along with collocational constraints and limited range of word class on the part of some TL lexical items. These constraints make direct translation impossible. To overcome such constraints, an array of translation procedures is employed, depending on the nature of the difficulty, the context in which an instance occurs, the possible alternatives available to tackle the constraint and translator's orientation towards the text and the audience.

In relation to the semantic level, which is the central issue in translating informative texts, including journalistic texts, four areas of meaning can be particularly problematic, namely: limited range of meaning, polysemy, idioms and metaphors. In the case of idioms and metaphors it is not only meaning that matters, but also the stylistic effects produced. This requires translators to opt for a semantically and stylistically equivalent idiom or metaphor in the first instance. If this is impossible, translators should look at idioms and metaphors having the same meaning but a different stylistic form. Despite the importance of the stylistic effects created by idioms and metaphors in journalism, they are sometimes paraphrased into unidiomatic and non-metaphorical expressions, and in extreme cases, they are even completely omitted.

The syntactic level is always a more flexible level than the semantic one in terms of translation. Yet, in the case of English-Kurdish translation, there are issues to be taken into consideration. Lacunae in structure for some English syntactic constructions, limited range of structure in the case of reporting direct speech and voice can cause translation difficulties. 
Translation procedures such as expansion, reduction, modulation and transposition can be particularly helpful to deal with these translation difficulties.

At the cultural level, any culture-specific term can be an impediment in translation since the focus is not only on the meaning of the cultural term, but also on how it is perceived by members of the TL community. In the case of English-Kurdish translation, the areas of translation difficulty identified at the cultural level are: lexical and semantic cultural gaps, proper nouns, appellative (addressing people's names) and new institutional terms. The translation constraints encountered at the cultural level have necessitated the use of various translation procedures, such as: literal translation, transference/transliteration and cultural adaptation.

\section{References:}

1. Anokhina, T. (2013). 'The linguistic lacunicon: cognitive mapping in schemes and terms'. Journal of Education Culture and Society, 1, 166-174.

2. Baker, M. (2011). In Other Words: A Coursebook on Translation (2nd ed.). London and New York: Routledge.

3. Chesterman, A. (1997). Memes of Translation. Amsterdam and Philadelphia, PA: John Benjamins.

4. Collins English Dictionary (2006). New York: Harper Collins Publishers.

5. Dickins, J., Hervey, S. and Higgins, I. (2002). Thinking Arabic Translation: A Course in Translation Method: Arabic to English. London and New York: Routledge.

6. Klaudy, K. (2009). Explicitation. In: Baker, M. and Saldanha, G. (eds.) Routledge Encyclopedia of Translation Studies (pp. 104-108) (2nd ed.). London and New York: Routledge.

7. Lakoff, G. and Johnson, M. (2013). Metaphors We Live By (2nd ed.). Chicago: Chicago University Press.

8. Newmark, P. (1988). A Textbook of Translation. Hemel Hempstead: Prentice Hall International.

9. Nida, E. A. (1964). Toward a Science of Translating. Leiden: E. J. Brill.

10. Rasul, S. H. (2015). Procedures and Strategies in English-Kurdish Translation of Written Media Discourse. Unpublished PhD Thesis, University of Leeds, Leeds, UK.

11. Vinay, J.-P. and Darbelnet, J. (1995). Comparative Stylistics of French and English: $A$ Methodology for Translation. Amsterdam and Philadelphia: John Benjamins. 